\title{
A COMPARATIVE STUDY OF SUPINE TRANSGLUTEAL EXTRACORPOREAL SHOCKWAVE LITHOTRIPSY AND URETEROSCOPY FOR THE MANAGEMENT OF DISTAL URETERIC STONES
}

\author{
${ }_{1}^{1}$ Assistant Professor, Department of Urology, Madras Medical College. \\ ${ }^{2}$ Postgraduate, Department of Urology, Madras Medical College. \\ 3Postgraduate, Department of Urology, Madras Medical College. \\ ${ }^{4}$ Professor, Department of Urology, Madras Medical College.
}

Karunamoorthy Ramaraju1, Karthik Rajan², Arivazhagan Kanagaraju3 , Ilamparuthi Chennakrishnan4

\section{ABSTRACT}

The ureteral calculus in general presents as acute colicky pain and the aim of treatment is to achieve complete stone clearance with minimal morbidity for the patient. Of the available treatment options for the management of lower ureteric stones, semirigid ureterorenoscopy with intracorporeal lithotripsy has the best results with little morbidity. However, ESWL is a safe and non-invasive technique with minimal morbidity. We have studied the outcomes of ESWL for distal ureteric stones and compared it with the ureterorenoscopy which is the current modality of choice.

\section{METHODS}

A total of 120 patients were included in the study. They were randomly divided into two groups by an independent observer into group A (70 patients) and group B (50 patients). The patients in group A were managed by supine transgluteal ESWL as described below and those in group B were managed by semirigid ureteroscopy. Patients were followed up at 15 days, 30 days and 90 days. Failure was defined as the presence of fragments of any size in the followup film 3 months after the final ESWL session.

\section{RESULTS}

The demographic parameters and stone characteristics were comparable between the two groups. In our study, overall stonefree rate at three months was $93.8 \%(107 / 114)$. Clearance in the ESWL group was $89.4 \%(59 / 66)$ and in the URS group was $100 \%$ (48/48). This difference; however, was not statistically significant. However, there was an increased incidence of complications in the URS group, ( $24.2 \%$ vs. $39.6 \%$ ), though most of the complications were mild requiring no active intervention. This difference was also not statistically significant $(\mathrm{p}=0.10)$.

\section{CONCLUSION}

Supine transgluteal SWL for distal ureteric stones, the results are comparable with that of ureteroscopy with intracorporeal lithotripsy with specific advantages in carefully selected patients. It can be recommended as a non-invasive alternative for patients who are not fit or unwilling for surgery.

\section{KEYWORDS:}

ESWL, Ureteroscopy, Distal Ureteric Stones.

HOW TO CITE THIS ARTICLE: Ramaraju K, Rajan K, Kanagaraju A, et al. A comparative study of supine transgluteal extracorporeal shockwave lithotripsy and ureteroscopy for the management of distal ureteric stones. J. Evolution Med. Dent. Sci. 2016;5(77): 56845687, DOI: $10.14260 /$ jemds/2016/1282

\section{INTRODUCTION}

The ureteral calculus in general presents as acute colicky pain and the aim of treatment is to achieve complete stone clearance with minimal morbidity for the patient. Currently, several surgical options are available for ureteral calculus management. Advances in ureterorenoscope, newer methods of intracorporeal stone fragmentation, laparoscopic methods and developments in extracorporeal shockwave lithotripsy have resulted in changes with regard to the use of treatment modalities for ureteral stones. ${ }^{1}$ Extracorporeal shockwave lithotripsy (ESWL) is the least invasive treatment for calculi of the upper urinary tract and it is recommended as first line therapy. ${ }^{2}$ However, ESWL has a variable success rate.3,4

Financial or Other, Competing Interest: None.

Submission 14-08-2016, Peer Review 12-09-2016,

Acceptance 19-09-2016, Published 23-09-2016.

Corresponding Author:

Karunamoorthy Ramaraju,

No. 2130, Arya, Flat 2B, 12 $2^{\text {th }}$ Main Road

L-Block, Anna Nagar, Chennai-600040.

E-mail: drrkaruna@yahoo.co.in

DOI: $10.14260 /$ jemds/2016/1282
The role of ureteric stents on the outcome of ESWL is a dilemma, with no clear-cut recommendations. Stents are unavoidable in some cases like obstruction and sepsis. Ureteric stents does not affect the treatment outcomes. ${ }^{5,6}$ The density of stone measured by NCCT, stone Hounsfield Unit (HU) varies with stone composition and determines the fragility of a calculus which ultimately governs the clinical outcome in ESWL. NCCT because of its easy availability, excellent sensitivity and very high resolution capability is a good modality for the measurement of stone density.

Majority of urinary tract stones are managed with ESWL in the western world. For the mid or distal ureteric stones, the prone position was adapted, with shockwave head in contact with the patient's anterior abdomen. It is a safe and effective method of treating stones in the distal ureter.7,8

Of the available treatment options for the management of lower ureteric stones, semirigid ureterorenoscopy with intracorporeal lithotripsy has the best of the results with relation to stone clearance and morbidity of treatment. However, ESWL is a safe and non-invasive technique which can be applied to patients with minimal morbidity. We have studied the outcomes of ESWL for distal ureteric stones and 
compared it with the ureterorenoscopy which is the current modality of choice.

\section{MATERIALS AND METHODS}

The study was conducted in the Institute of Urology, Rajiv Gandhi Government General Hospital and Madras Medical College, Chennai from September 2014 to February 2015 on the patients who presented for the management of distal ureteric stones. Ethical clearance was taken from the Institutional Ethics Committee prior to the start of the study. All the patients were informed about the study and a consent form was signed by them.

We included patients with radio-opaque, solitary, unilateral, previously untreated distal ureteric stones in this study. Patients who were previously treated in the form of percutaneous nephrostomy or ureteric stents, patients with bilateral calculi, elevated renal parameters, patients with anatomic abnormalities and those with coagulation disorders, sepsis, pregnancy were excluded. A total of 120 patients selected were included in the study. They were randomly divided into two groups by an independent observer into group A (70 patients) and group B (50 patients). The patients in group A were managed by supine transgluteal ESWL as described below and those in group B were managed by semirigid ureteroscopy with intracorporeal pneumatic lithotripsy in the usual way. A total of 6 patients, 4 from ESWL group and 2 from URS group did not turn up for follow-up and hence were excluded from the study.

\section{Procedure of Supine Transgluteal ESWL}

The patients are asked to come with overnight fasting and are premedicated with Inj. Pentazocine $30 \mathrm{mg}$ and Inj. Promethazine HCL 25 mg intramuscularly 30 minutes before the procedure. The patient was placed in a supine position with a 40-degree tilt to focus the shockwaves through the greater sciatic notch. SWL was done with Dornier Compact Delta II (Electromagnetic Generator) device as outpatient procedure. Stone was localised with fluoroscopy. 2500 shockwaves were given in each session. The energy intensity was kept between 4 and 5 and the shockwave rate was fixed at 60 per minute.

After each session of treatment, patients were observed for 2-3 hours and allowed to go home. Patients were explained about the post-treatment haematuria, dysuria and passage of stone fragment in the urine. Patients advised to maintain adequate oral fluids. Patients were advised oral antibiotic, analgesic and $\mathrm{H}_{2}$ blocker for 5 days.

In cases of patient developing complications in any of the two groups, they were managed appropriately with or without admission with respect to the concerned complication.

Patients were followed up at 15 days, 30 days and 90 days or whenever patients had unusual urinary complaints after the procedure. If patient had inadequate fragmentation at 15 days' visit, evident on X-ray/ultrasound, a second session of SWL is done. For patients undergoing URS, at the 15 days' visit the stent was removed by cystoscopy under local anaesthesia using 19 French sheath if the stones were completely cleared on X-ray/ultrasound. If patient had larger fragment persisting at 15 days' visit, evident on X-ray/ultrasound, a second procedure of URS is done.
Failure was defined as the presence of fragments of any size in the follow-up film 3 months after the final ESWL session. The patient's followup was terminated if the patient cleared the stone with procedure or a secondary treatment was selected for the failure.

For each group, haematuria, fever, steinstrasse, ureteric colic requiring hospital admissions, lower urinary tract symptoms, stone clearance, number of ESWL sessions, and secondary procedures were recorded. The DJ stent was removed when the stone disappeared or at three months whichever is earlier.

\section{RESULTS}

The study comprised of 114 patients of distal ureteric calculus divided into two groups, 66 patients in ESWL group and 48 patients in URS group. Age of the patients ranged from 18-64 yrs. and most patients were in 21-40 years of age. There were 54 male and 12 female patients in ESWL and 40 males and 8 females in URSL group. The age and sex distribution was comparable between the two groups with $\mathrm{p}$ values being 0.6 and 0.581 respectively.

The stone characteristics were compared between the two groups. The comparison is shown in Table 1. Left-sided stones predominated in both the study groups. The size and side of the stones in both the groups were comparable with the $p$ values being not significant.

In our study, overall stone-free rate at three months was 93.8\% (107/114). Clearance in the ESWL group was $89.4 \%$ (59/66) and in the URS group was 100\% (48/48) (Table 3). This difference; however, was not statistically significant. Though the number of procedures required in the ESWL group were more compared to URS group, the difference again was not statistically significant (Table 2 ).

Clearance according to size: $6 \mathrm{~mm}$ to $10 \mathrm{~mm}$ were $100 \%$, $11 \mathrm{~mm}$ to $15 \mathrm{~mm}$ were $88.2 \%$ and $16 \mathrm{~mm}$ to $20 \mathrm{~mm}$ were $81.2 \%$. 6.2\% patients did not have successful outcome. $10.6 \%$ patients did not have successful outcome in the ESWL group, had incomplete fragmentation. Two cases had effective fragmentation but incomplete clearance and so underwent URS with stone extraction.

The complication rates between the two groups were compared which showed that there was an increased incidence of complications in the URS group $(24.2 \%$ vs. $39.6 \%$ ), though most of the complications were mild requiring no active intervention. This difference was also not statistically significant $(\mathrm{p}=0.10)$.

\begin{tabular}{|c|c|c|c|}
\hline \multirow{2}{*}{ SIDE } & \multicolumn{2}{|c|}{ No. of Patients } & \multirow{2}{*}{ P Value } \\
\cline { 2 - 3 } & $\begin{array}{c}\text { ESWL } \\
(\mathbf{n = 6 6 )}\end{array}$ & $\begin{array}{c}\text { URSL } \\
(\mathbf{n = 4 8})\end{array}$ & \\
\hline Right & 32 & 21 & \multirow{2}{*}{0.817} \\
\hline Left & 34 & 27 & \\
\hline SIZE & & & \multirow{2}{*}{0.654} \\
\hline $6-10 \mathrm{~mm}$ & 38 & 26 & \\
\hline $11-15 \mathrm{~mm}$ & 19 & 15 & \\
\hline $16-20 \mathrm{~mm}$ & 9 & 7 & \multirow{2}{*}{ Table 1: Stone Distribution in both the Groups } \\
\hline \multicolumn{2}{|c|}{} \\
\hline
\end{tabular}




\begin{tabular}{|c|c|c|c|}
\hline \multirow{2}{*}{ No. of Sittings } & \multicolumn{2}{|c|}{ No. of Patients } & \multirow{2}{*}{ P value } \\
\cline { 2 - 3 } & $\begin{array}{c}\text { ESWL } \\
(\mathbf{n = 6 6 )}\end{array}$ & $\begin{array}{c}\text { URSL } \\
(\mathbf{n = 4 8 )}\end{array}$ & \\
\hline One & $52(78.78 \%)$ & $45(93.7 \%)$ & \multirow{2}{*}{0.235} \\
\hline Two & $7(10.6 \%)$ & $3(6.3 \%)$ & \\
\hline Total & $\mathbf{5 9 ( 8 9 . 4 \% )}$ & $\mathbf{4 8}(\mathbf{1 0 0} \%)$ & \\
\hline \multicolumn{3}{|c|}{ Table 2: Number of Procedures in both the Groups } \\
\hline
\end{tabular}

\begin{tabular}{|c|c|c|c|}
\hline \multirow{2}{*}{ Size } & \multicolumn{2}{|c|}{ No. of Patients } & \multirow{2}{*}{$\begin{array}{c}P \\
\text { value }\end{array}$} \\
\hline & ESWL (n=66) & URSL $(n=48)$ & \\
\hline 6-10 mm & $38 / 38(100 \%)$ & $26 / 26(100 \%)$ & \multirow{4}{*}{0.65} \\
\hline $\begin{array}{c}11-15 \\
\mathrm{~mm}\end{array}$ & $15 / 19(79 \%)$ & $15 / 15(100 \%)$ & \\
\hline $\begin{array}{c}16-20 \\
\mathrm{~mm}\end{array}$ & $6 / 9(66.7 \%)$ & $7 / 7(100 \%)$ & \\
\hline Total & $59 / 66(89.4 \%)$ & $48 / 48(100 \%)$ & \\
\hline \multicolumn{4}{|c|}{ Table 3: Stone-Free rate According to Stone Size } \\
\hline
\end{tabular}

\begin{tabular}{|c|c|c|c|}
\hline \multirow[b]{2}{*}{ Complications } & \multicolumn{2}{|c|}{ No. of Patients } & \multirow[b]{2}{*}{$P$ value } \\
\hline & $\begin{array}{c}\text { ESWL } \\
(n=66)\end{array}$ & $\begin{array}{c}\text { URSL } \\
(n=48)\end{array}$ & \\
\hline Haematuria & $6(9.09 \%)$ & $8(16.7 \%)$ & \multirow{5}{*}{0.10} \\
\hline Fever & $3(4.55 \%)$ & $8(16.7 \%)$ & \\
\hline Steinstrasse & $3(4.5 \%)$ & $2(4.2 \%)$ & \\
\hline Ureteric Colic & $4(6.06 \%)$ & $1(2.08 \%)$ & \\
\hline Total & $16(24.2 \%)$ & $19(39.6 \%)$ & \\
\hline Table 4 & mplication $R c$ & es in both Gro & \\
\hline
\end{tabular}

\section{DISCUSSION}

SWL has revolutionised the management of urolithiasis worldwide. Non-invasiveness with high efficacy has made SWL gain rapid worldwide acceptance. SWL and ureteroscopy recently used in the management of distal ureteric stones have valid advantages and disadvantages. Supporters of SWL claim that it is effective and noninvasive, is associated with less morbidity, requires lesser anaesthesia than ureteroscopy, and seldom requires ureteric stents. Critics argue that the success rates are not as high as those of ureteroscopy, equipment availability may be limited, visualisation of the stone is often difficult, attainment of a stone-free state requires a longer time and follow-up, re-treatment rates are higher, and costs are higher. Supporters of ureteroscopy claim that it is highly successful and minimally invasive, is associated with minimal morbidity, can be used with larger and multiple stones, and has high immediate stone-free rates. Critics argue that it requires specialised training, requires more anaesthesia, and more often requires ureteric stent placement.

The standard treatments for the distal ureteric stones not amenable to conservative approach are SWL and ureteroscopy. ${ }^{9}$ Previously, distal ureteric calculus managed by SWL was done in the prone position with discomfort to many patients. Supine position SWL was not considered because of hindrance by the pelvic bone preventing the shockwave from reaching the distal ureter. In prone position, the shockwaves need to travel through the abdominal wall, intestines and/or the bladder before reaching the target stone. Hence, the distance travelled by the shockwaves measured as the skin-tostone distance (SSD) is significantly greater. SSD is an independent predictor of outcome for SWL. ${ }^{10}$ Further, the shockwaves are attenuated by bowel gas as it traverses through them to reach the target stone.
The transgluteal supine SWL is ideal for targeting the distal ureter through the greater sciatic notch, thus bypassing the bony impedance by the pelvis. At times, the shockwave may strike the sciatic nerve near the focal point and cause pain, which can be easily managed by slight changes in patient positioning and the treatment angle. The success of management in this position is highly operator dependent. The supine position SWL is far comfortable for many patients, particularly for the elderly, the obese and those with physical disability/poor mobility.

Comparing the patient and stone characteristics, no significant difference was observed between the two groups. Males form the majority of the patients in both the groups (82\%). The stone-free rates for the supine transgluteal SWL group was $89 \%$ and that for the URS group was $100 \%$, in contrast to reported success of $69 \%$ by prone position SWL for the distal ureteric stones. 11

\section{The Advantages of Supine Transgluteal SWL in Adults are} as follows:

1. Regional anaesthesia is not needed - hence, fitness for anaesthesia and its complications are excluded.

2. Non-invasive intervention - URS and ICL procedure related complications are avoided.

3. Stents not needed - hence, stent related LUTS complications are avoided and the need for a second procedure to remove them is also excluded.

4. Can be satisfactorily contemplated in obese patients who have difficulties in patient positioning and the procedure.

5. Performed on an outpatient basis.

The failure of supine transgluteal SWL in our study was in $7(10.6 \%)$ patients and they were managed by ureteroscopy and lithotripsy. Two of these patients' stones were fragmented but were not cleared successfully. The reasons for other failures to SWL are not clear, but may be due to SSD, pain during treatment and the hardness of the stone.

The success of transgluteal ESWL for distal ureteric stones has recently been reported by other studies worldwide. Lu et $\mathrm{al}^{12}$ and Sun et $\mathrm{al}^{13}$ have reported use of the technique in the treatment of distal ureteric stones in both children and adults. They did not; however, compare outcomes with those of the prone approach. Istanbulluoglu et al ${ }^{14}$; however, retrospectively compared the supine and prone approaches and reported superiority of the supine approach as in the present series.

The present study confirms that the outcome of ESWL via the transgluteal approach to the distal ureter was nearly equivalent to the ureteroscopy and superior in terms of postprocedure complications especially lower urinary tract symptoms.

\section{CONCLUSION}

Supine transgluteal SWL for distal ureteric stones, the results are comparable with that of ureteroscopy with intracorporeal lithotripsy with specific advantages like

a. Outpatient procedure.

b. Non-invasive intervention.

c. Good analgesia is sufficient, anaesthesia not necessary.

No need of stents, hence no stent related LUTS complications or secondary procedures to remove them. 


\section{REFERENCES}

1. Anagnostou T, Tolley D. Management of ureteric stones. Eur Urol 2004;45(6):714-21.

2. Segura JW, Preminger GM, Assimos DG, et al. Ureteral stones clinical guidelines panel summary report on the management of ureteral calculi. The American Urological Association. J Urol 1997;158(5):1915-21.

3. Liong ML, Clayman RV, Gittes RF, et al. Treatment options for proximal ureteral urolithiasis: review and recommendations. J Urol 1989;141(3):504-9.

4. Grasso M, Beaghler M, Loisides P. The case for primary endoscopic management of upper urinary tract calculi: II. Cost and outcome assessment of 112 primary ureteral calculi. Urology 1995;45(3):372-6.

5. Mobley TB, Myers DA, Jenkins JM, et al. Effects of stents on lithotripsy of ureteral calculi: treatment results with 18,825 calculi using the Lithostar lithotripter. J Urol 1994;152(1):53-6.

6. Cass AS. Nonstent or noncatheter extracorporeal shockwave lithotripsy for ureteral stones. Urology 1994; 43(2):178-81.

7. Jenkins AD, Gillenwater JY. Extracorporeal shock wave lithotripsy in the prone position: treatment of stones in the distal ureter or anomalous kidney. J Urol 1988;139(5):911-5.
8. Zehntner $\mathrm{CH}$, Marth D, Zingg EJ. ESWL treatment with ventral shock-wave application: therapy of iliac and distal ureteral calculi. Urology 1991;38(1):51-3.

9. Preminger GM, Tiselius HG, Assimos DG, et al. 2007 guideline for the management of ureteral calculi. J Urol 2007;178(6):2418-34.

10. Patel T, Kozakowski K, Hruby G, et al. Skin to stone distance is an independent predictor of stone-free status following shockwave lithotripsy. J Endourol 2009;23(9):1383-5.

11. Elashry OM, Elgamasy AK, Sabaa MA, et al. Ureteroscopic management of lower ureteric calculi: a 15-year singlecentre. BJU Int 2008;102(8):1010-7.

12. Lu J, Sun X, He L. Sciaticum majus foramen and sciaticum minus foramen as the path of SWL in the supine position to treat distal ureteral stone. Urol Res 2010;38(6): 417-20.

13. Sun $\mathrm{X}, \mathrm{He} \mathrm{L}, \mathrm{Lu} \mathrm{J}$, et al. Greater and lesser ischiatic foramina as path of shock wave lithotripsy for distal ureteral stone in children. J Urol 2010;184(2):665-8.

14. Istanbulluoglu MO, Hoscan MB, Tekin MI, et al. Shock wave lithotripsy for distal ureteric stones: supine or prone. Urol Res 2011;39(3):177-80. 